\title{
Long-term study of the impact of temperature changes, material aging and service load on the strains of a reinforced concrete structure
}

\author{
Adam Kanciruk* \\ Strata Mechanics Research Institute of Polish Academy of Sciences, Cracow, Poland
}

\begin{abstract}
The article discusses five year long measurements of strains of a concrete floor of a hangar. That hangar, originally meant for servicing light military aircraft, was rebuilt with a view to making it fit for servicing larger and heavier passenger planes. As part of that redevelopment, a new floor - reinforced concrete slab, capable of withstanding the weight of the planes - was constructed. In the areas of the floor where the greatest loads occur, ie. in the areas of the concrete slab on which the wheels of the three undercarriage legs rest, three strain rosettes were installed so that the slab strains could be measured. The rosettes were connected to two meters dataloggers. The latter were programmed in such a way as to register the measured strains and additionally temperatures many times during every 24 hours. The monitoring process, conducted in such an automatic way, demonstrated the occurrence of strains resulting from service load, aging of the reinforced concrete, as well as changes in its temperature.
\end{abstract}

Keywords: construction, metrology, strain rosette

\section{Introduction}

The research location is a hangar originally built for servicing light military aircraft whose take-off mass does not exceed $9,100 \mathrm{~kg}$. That hangar is a hall whose dimensions are $84 \times 42.5 \mathrm{~m}$, with one of the longer sides being a sliding door. Inside the hangar, two planes of the size corresponding to an Airbus A320 or Boeing 737 can easily be fit, which is why the place was rebuilt so that it could become apt for servicing passenger aircraft, mostly the types mentioned above. Figure 1 presents the inside of the hangar before the redevelopment. The mass of a plane such as the Airbus A320 approximates $42000 \mathrm{~kg}$ (without passengers, cargo and fuel) [1], which is why the load from the wheels of its undercarriage legs damaged the floor that was unfit for such loads (Fig. 1). Additionally, the laboratory research of the samples of that floor demonstrated considerable irregularities of the construction. Therefore, as part of the hangar redevelopment, a decision was made to partly replace the floor.

\footnotetext{
*Corresponding author: kanciruk@img-pan.krakow.pl
} 


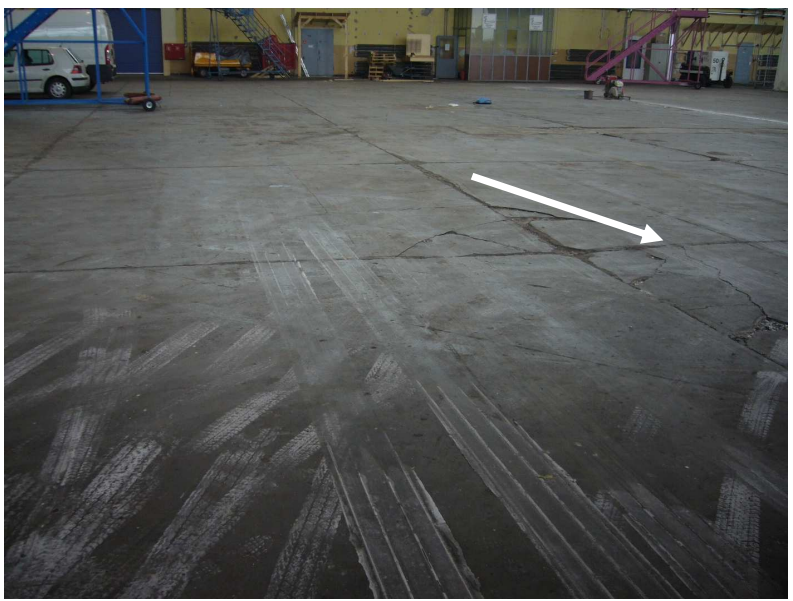

Fig. 1. The inside of the hangar. Damages to the floor are visible.

\section{Construction of the new hangar floor}

Figure 2 presents, in a simplified way, the construction of the eastern part of the hangar floor after redevelopment of the place. The western part is its mirror image. The construction of the roof was left largely unchanged, which - due to its height - makes it impossible to park an entire plane inside the hangar. It was assumed that the control surfaces and the back of the fuselage will be protruding outside the gate during servicing.

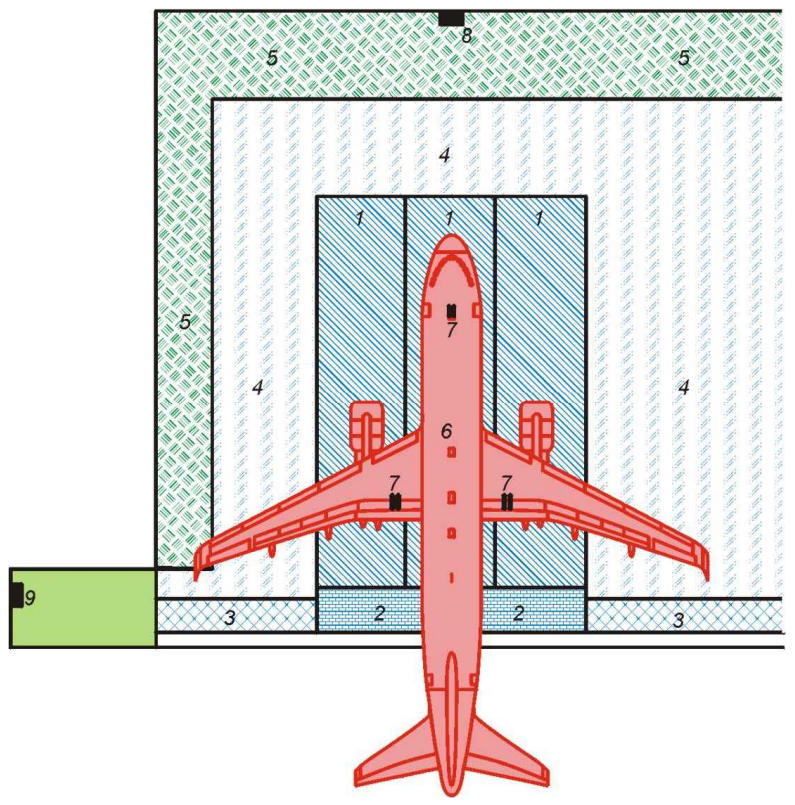

Fig. 2. Scheme of the hangar floor after the redevelopment, the eastern part: 1- constituent slabs of the main slab, 2,3 - slabs in the door area, 4 - buffer slab, 5 - fragment of the previous slab, 6 -

silhouette of an Airbus A320, 7 - undercarriage wheels, 8,9- measuring instruments - recorders.

In the construction process of all the slabs, i.e. the main one, the buffer one and the slabs in the door area, the same concrete was used. Each of the slabs is $30 \mathrm{~cm}$ thick, and they all rest on the same base, having a gliding layer underneath them. The slabs differ only 
with respect to the concrete reinforcement. The main slab, whose dimensions are $26.25 \times 18$ $\mathrm{m}$, was constructed as three separate $6 \mathrm{~m}$ wide slabs, surrounded by construction joints. Additionally, each of these components of the main slabs is cut up with contraction joints.

\section{Rationale for installing research equipment in the hangar}

Taking into consideration the damages to the previous hangar floor, it was decided that measuring equipment would be installed in the hangar with a view to determining the strains of the new floor during its exploitation. These strains might be caused by contraction and drying up [2] of the concrete used to build the floor, as well as by changes in the temperature and the load from the planes serviced in the hangar. That load poses a particular threat to these parts of the floor on which the wheels of the three undercarriage legs rest (Fig. 2). The prescribed location spot of the front leg (in the nose) during parking is precisely determined. At the same time, the wheels of the main legs (under the wings) may rest in different places, depending on the type of aircraft being serviced, although the latter happens mostly to be the Airbus A320. Also, it is not necessary that the axis of the fuselage of a plane parked in a hangar should overlap with the axis of the main slab (Fig. 2).

It is obvious that, due to the works conducted in the hangar, measuring the floor strains in a manual way cannot be allowed. It is also impossible to apply instruments that would hamper servicing of the planes in any way. Therefore, it was decided that an automatic measurement system would be installed in the hangar. The system's objective is to perform measurements of the strains to the floor with a frequency sufficient to determine the impact of various factors upon these deformations. Of the different types of measurement transducers, vibrating wire extensometers were selected - simple instruments characterized by high reliability, solid long-term metrological parameters, as well as their adjustment to immersion in a semi-liquid concrete mix before it solidifies.

\section{Installing measuring rosettes in the hangar's main (eastern) slab}

The measuring system (Fig. 3) consists of three equilateral strain rosettes and two meters strain recorders. The rosettes were installed in the spots where the biggest load from the undercarriage wheels of the serviced Airbus A320 planes is expected. For clarity's sake, the rosettes presented in Figure 3 are magnified; as a matter of fact, their real dimensions correspond to the dimensions of the small triangles pictured inside them. Each of the rosettes is built of three identical vibrating wire transducers that had been set in the floor's body, some $5 \mathrm{~cm}$ above its lower surface adjacent to the gliding layer (Fig. 4). In order to ensure proper identification of particular extensometers, they were marked with three colored ,jackets" (yellow, green and blue) pulled over their wires (Fig. 3, 4). To measure the temperature of the concrete in the place where the rosettes are set, three thermistors were used. Thermistors of the same type were applied to measure the temperature of the air inside the hangar. 


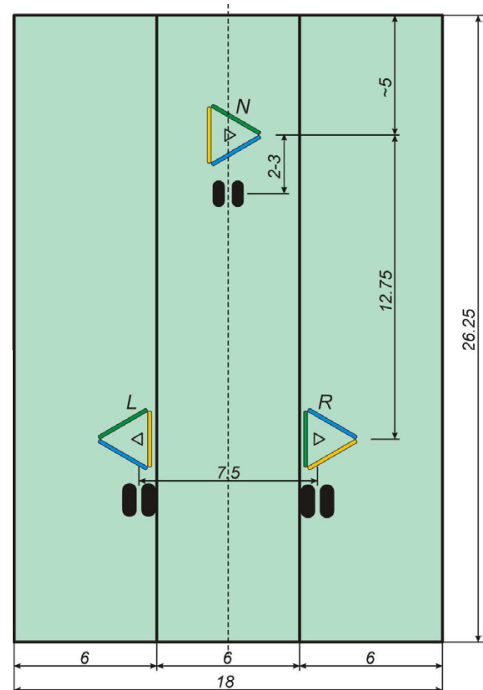

Fig. 3. Distribution of the strain rosettes in the main slab.

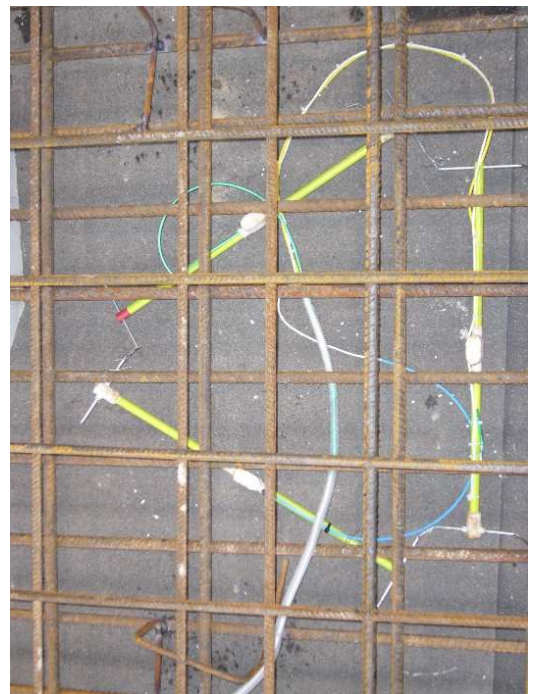

Fig. 4. The rosette installed in the area of the load from the wheels of the left main undercarriage leg.

Unfortunately, the refurbishment of the hangar roof that followed the construction of the floor, along with the installation of the new gate, necessitated a minor correction of the prescribed location of the planes in the hangar, which, however, was of great importance in the light of the conducted measurements. Under the correction, the planes are parked in the hangar in such a way that the undercarriage wheels do not stop above the installed rosettes, but some 2 meters above them, looking from the plane's nose (Fig. 3, 5). Thus, the deformations calculated on the basis of the readings of the extensometers are smaller than in the places of the wheels' resistance, and they are of the opposite sign (compression instead of stretching).

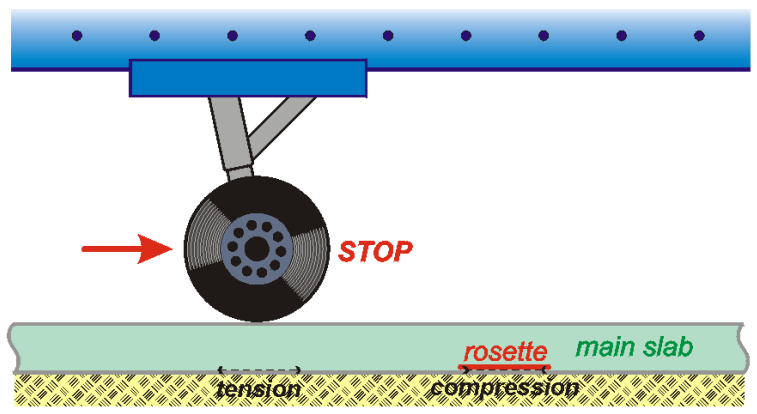

Fig. 5. The position of the plane's undercarriage wheels in relation to the rosettes.

\section{Measurements and recording the results. Interpreting the obtained data}

All the extensometers and thermistors of the rosettes were connected to two meters recorders $(8,9-$ Fig. 2$)$. The period of measurement repetition for these instruments can be readjusted. In the first period of its activity, lasting ca. 3 years, the system performed 50 measurement a day, a number which was later reduced to 25 measurements a day. Figure 6 presents the values of strains calculated on the basis of the readings of particular extensometers of the left rosette, as registered in November 2011. 

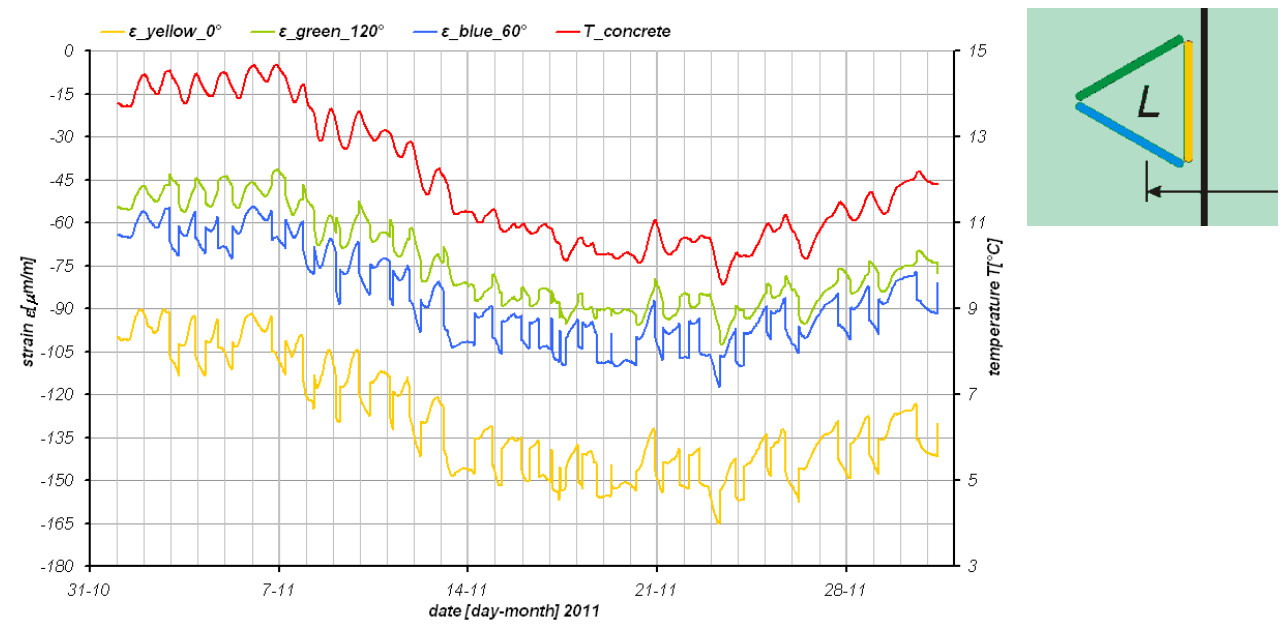

Fig. 6. Left strain rosette. The values of strains calculated on the basis of readings of particular extensometers ("yellow", "green" and "blue" one), under the temperature of the bottom layer of the floor (the temperature of concrete). November 2011.

All the extensometers reacted to changes in the temperature of concrete and exploitation loads in the way they were supposed to. Every time the plane was driven into the hangar and out of it, sudden changes in the strains of the main slab of the floor occurred, especially in the area where that slab was impacted by the main undercarriage legs' wheel load. These changes might be determined by means of a software developed specifically for that purpose. That software's task is to single out the deformations caused by the aforementioned load and, on that basis, establish the values of the major strains and their directions. Figure 7 presents the established values of the major strains for each case of parking the plane inside the hangar in November 2011. The plane driven into the hangar some time after midnight on November 11 caused compression strains of $20.25 \mu \mathrm{m} / \mathrm{m}$ and stretching strains of $6.35 \mu \mathrm{m} / \mathrm{m}$. The values of the strains obtained by means of the rosette placed in the area of the load from the wheels of the right undercarriage leg, in the same period of time, are almost two times smaller. The moments of driving the plane into the hangar and out of it coincide.

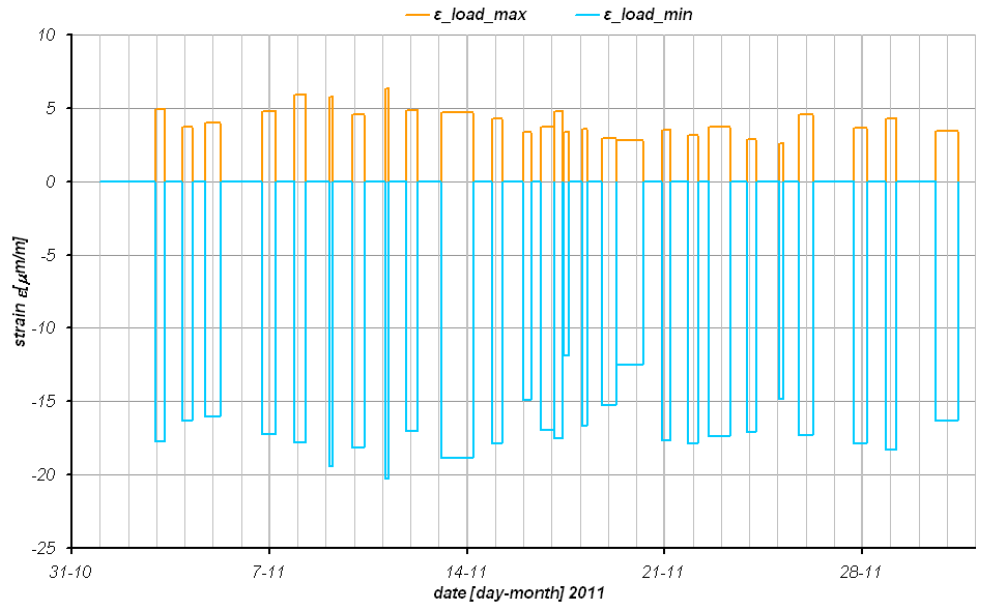

Fig. 7. Left rosette. The values of the major strains: maximum (epsAmax), minimum (epsAmin), caused by the load exerted on the main slab of the hangar floor by a plane. November 2011. 
Figure 7 presents just the values of the major strains of the floor caused by the wheel load from the main undercarriage legs. In order to depict graphically both the values and directions of the major strains of the hangar floor in the spots where the left and right rosettes were installed, the method explained in Figures 8-10 was adopted:

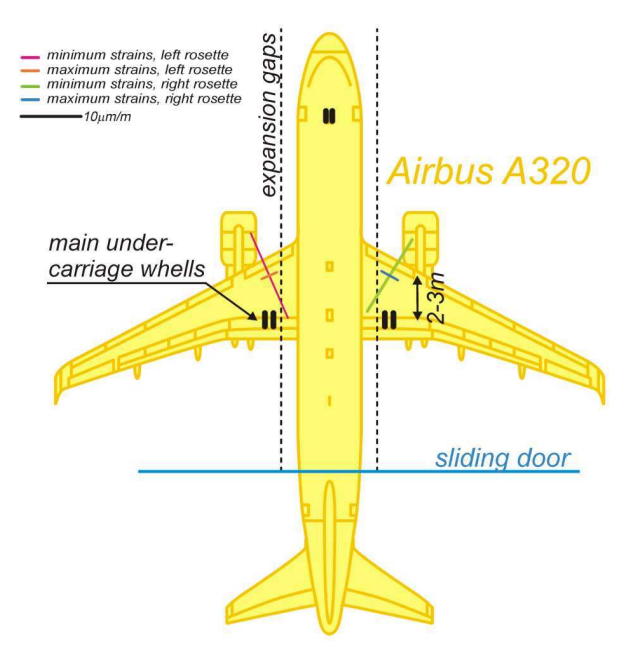

Fig. 8. Graphic interpretation of the measurement results: values and major strains for a single registered case of parking a plane inside the hangar.

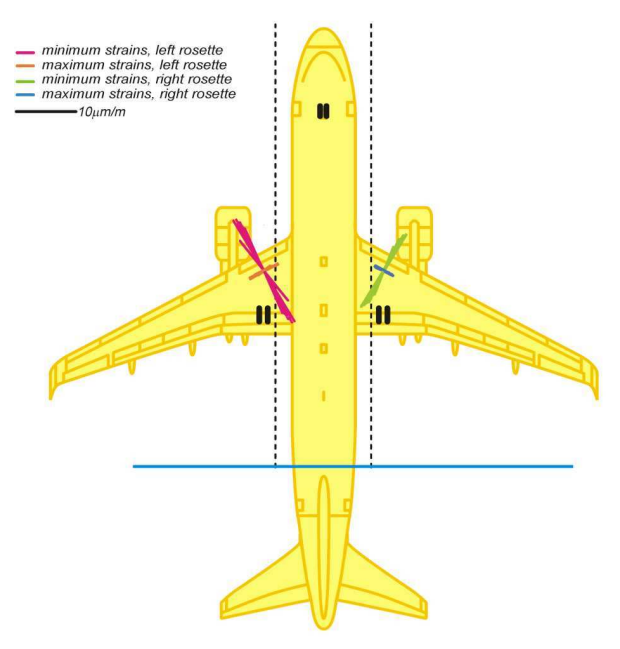

Fig. 9. Graphic interpretation of the measurement results: values and major strains for all the registered cases of parking a plane inside the hangar in November 2011.

Figure 8 presents an outline of a plane, with dotted lines marking longitudinal expansion gaps of the slabs making up the main slab. In front of the wheels of the main left undercarriage (in the direction of the plane's nose), two segments intersecting at a right angle were drawn. The intersection spot marks the place where a rosette is installed. The longer segment, drawn with a purple line, is oriented in accordance with the direction of the minimum, compression strains. The shorter, "red" segment, is oriented in accordance with the direction of the maximum, stretching strain. The lengths of the segments are proportional to the values of the deformations. Similarly, the segments represented by green and blue lines depict the major strains determined by the rosette installed in front of the wheels of the right main undercarriage. It is clearly visible that the outermost components of the main slab are dented towards the middle slab. It may certainly be attributed to the fact that each particular slab, as presented in Figure 3, is $6 \mathrm{~m}$ wide, and the spacing between the main undercarriage legs of an Airbus A320 is ca. $7.5 \mathrm{~m}$. Figure 9 presents all the registered cases of parking the plane inside the hangar in November 2011.

After removing the plane outline from Figure 9, adding the time axis to that Figure and properly locating all the cases of parking the plane in time, we obtain a clear temporal graph illustrating the values and directions of major strains calculated on the basis of the readings of both rosettes' extensometers (Fig. 10). The points where the pairs of segments intersect correspond, time-wise, to the midpoints of the periods when the plane was parked in the hangar. It can clearly be seen that the strains measured by the left rosette are larger than those measured by the right rosette.

Just like in Figure 10, the graphs were also drawn for each of the observation months that followed, from June 2011 to April 2016. Strains of the hangar floor are still being measured. 


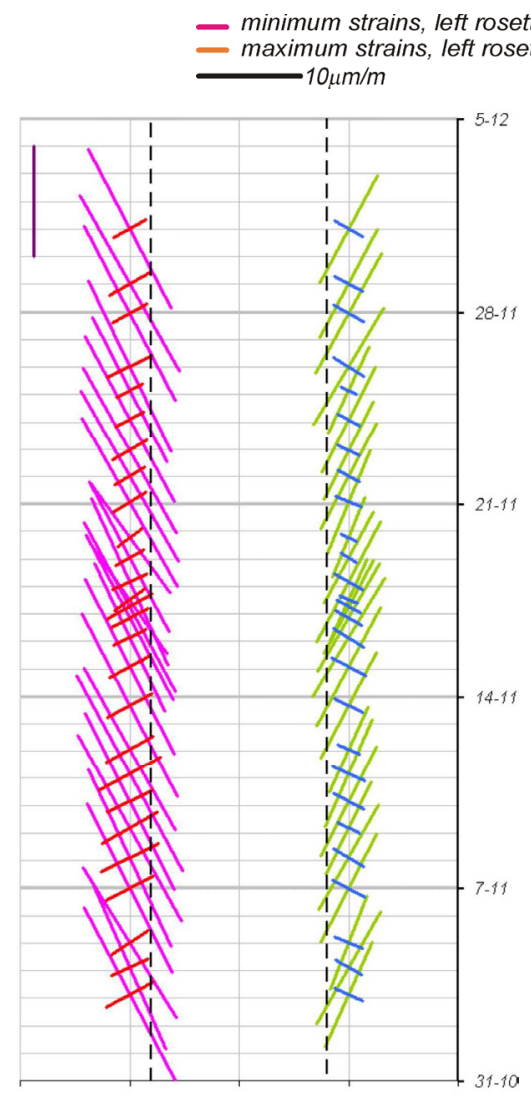

Fig. 10. Major strains of the components of the main slab in the rosettes' installation spots, for each case of parking the plane in the hangar in November 2011.
- minimum strains, right rosette

- maximum strains, right rosette

- - - expansion gaps

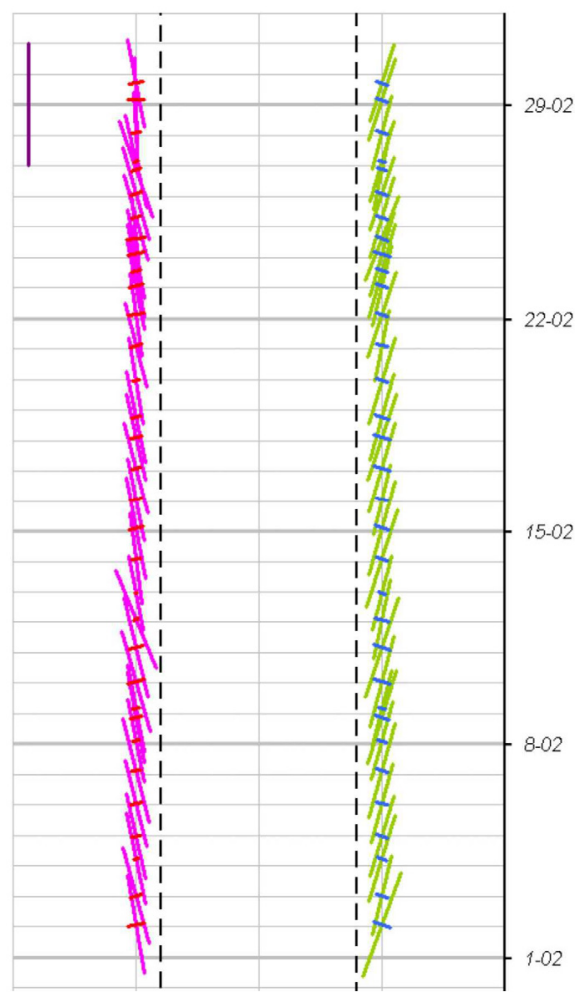

Fig. 11. Major strains of the slabs making up the main slab in the installation spots of the rosettes, for each case of parking a plane in the hangar in February 2016.

Figure 10 presents the strains recorded in November 2011, nine months after the main slab of the hangar floor was built. With time, due to the stabilization of the slab and its foundation, the values of the strains became considerably smaller. Figure 11 presents the strains of the slab in February 2016.

The deformations measured by both rosettes are not only smaller than in November 2011 (on February 2, 2016, the right rosette showed a compression strain of $9.09 \mu \mathrm{m} / \mathrm{m}$ and a stretching strain of $1.37 \mu \mathrm{m} / \mathrm{m}$ ), but also their values are very similar.

The tendency of temporal reduction in the values of strains caused by planes parked in the hangar is demonstrated by Figure 12 (left rosette) and Figure 13 (right rosette). Each pair of points - one above the dotted line and the other below it - represent the values of the strains: stretching and compression ones, respectively, caused by a single case of parking a plane in a hangar. The total number of such cases is 1,442 . 


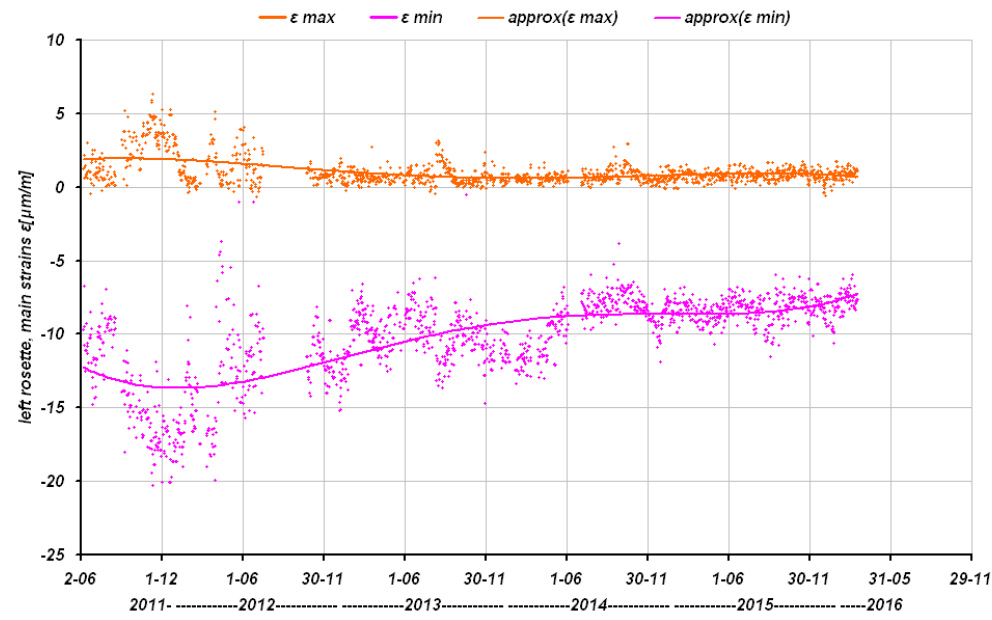

Fig. 12. Left rosette, the tendency of reduction in the values of maximum strains ( $\varepsilon_{-}$max) and minimum strains $\left(\varepsilon_{-} \mathrm{min}\right)$ for each case of parking a plane inside the hangar.

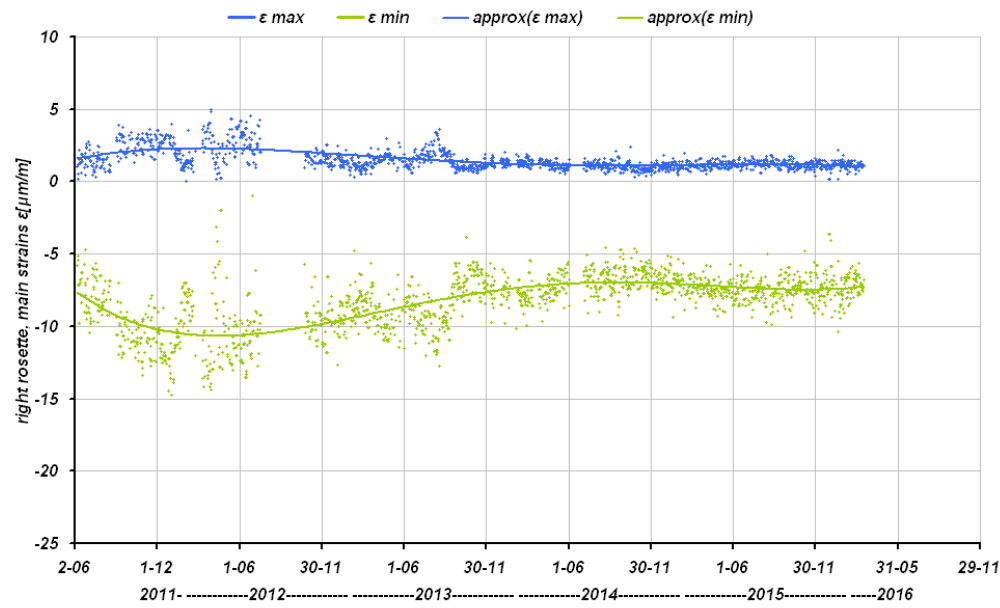

Fig. 13. Right rosette, the tendency of reduction in the values of maximum strains $\left(\varepsilon_{-} \max \right)$ and minimum strains $\left(\varepsilon_{-} \min \right)$ for each case of parking a plane inside the hangar.

Figures 12 and 13 clearly show that in the initial, year-long period of using the hangar, the values of the strains, module-wise, displayed a tendency to grow. That tendency later changed into a tendency to decrease, resulting in a stabilization of the strain values. Apart from the aforementioned reason for the stabilization of strains, there is also another potential reason, i.e. building a ca. $30 \mathrm{~cm}$ thick concrete parking slab of an area of $11 \mathrm{ha}$ in the vicinity of the hangar. That investment was carried out in the summer months of 2012. During that time, the hangar was not used, which is visible in Figures 12 and 13. for sure, the load from the constructed parking slab had an impact on migration of waters, which resulted in an increase in humidity and bearing capacity of the ground beneath the hangar. This is confirmed by increased water content in the servicing wells of the hangar, as well as by a small, several millimeter uplift of the floor along the gate.

As it was shown in Figure 5, in the current, prescribed location of the plane during the time of its parking, the wheels of the main undercarriage legs exert a load on the hangar floor in spots other than those in which the strain rosettes are installed. Still, of all the 1,442 
registered cases of parking the plane in the hangar, there was only one short instance when the aircraft was not parked in a prescribed manner. Figures 14 and 15 present the major strains of the hangar floor in the spots where the rosettes were installed.

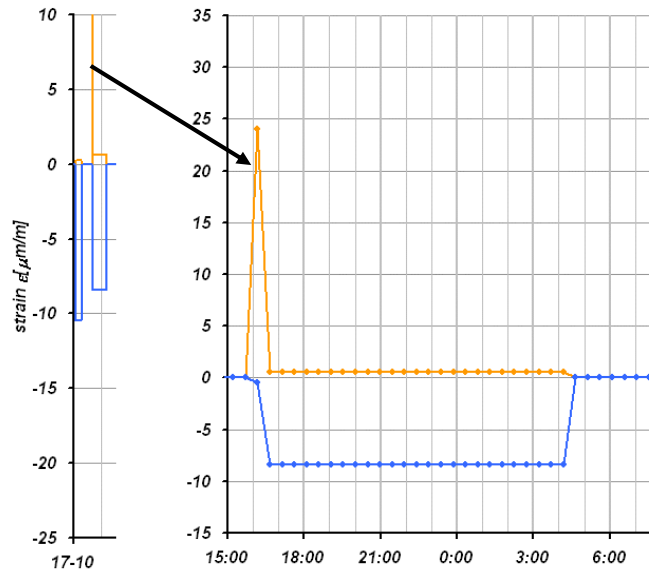

Fig. 14. Values of the major strains registered on October 17 and October 18, 2013. Left rosette.

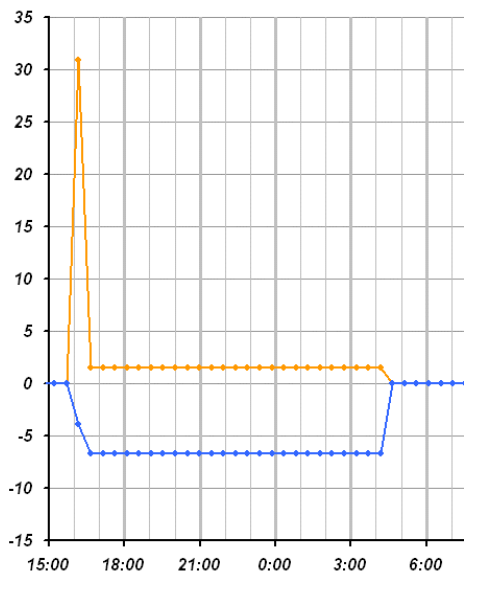

Fig. 15. Values of the major strains registered on October 17 and October 18, 2013. Right rosette.

On October 17, 2013, at 16:00, the values of the major strains for the left rosette were: $24 \mu \mathrm{m} / \mathrm{m}$ (stretching) and $0.5 \mu \mathrm{m} / \mathrm{m}$ (compression), and for the right rosette $-30.9 \mu \mathrm{m} / \mathrm{m}$ (stretching) and $3.9 \mu \mathrm{m} / \mathrm{m}$ (compression). The strains registered half an hour later were: 8.4 $\mu \mathrm{m} / \mathrm{m}$ (left rosette) and $6.7 \mu \mathrm{m} / \mathrm{m}$ (right rosette). Therefore, module-wise, they are 2.9 and 4.6 times smaller, respectively, than the values registered at 16:00. Most likely, in the initial stage of parking, the plane was driven considerably further into the hangar (it might have been the case that the wheels of the main undercarriage leg stopped in the rosettes' installation spot), and then pushed back to the prescribed position. It may be expected that, if such a situation had occurred on November 11, 2011, the registered stretching strains would have reached the values: $20.25 \times 2.9 \approx 59 \mu \mathrm{m} / \mathrm{m}$ for the left rosette, and $10.8 \times 4.6 \approx 50$ $\mu \mathrm{m} / \mathrm{m}$ for the right rosette.

The rosette located in the area of the load exerted by the wheels of the nose leg occupies the central position in relation to the longitudinal expansion gaps of the main slab, and thus it demonstrates considerably smaller usage strains as compared to the other rosettes, especially that the nose undercarriage leg bears not more than $15 \%$ of the plane's total weight. When analyzing the total strains, it can be noticed that the usage strains connected with the wheel load are a few $\mu \mathrm{m} / \mathrm{m}$, at best, so they cannot result in scratches. Thus, they pose no threat to the slab.

As each rosette was equipped with a thermistor, it is possible to estimate the thermal strains of the slabs in the spots where the rosettes were installed. These strains fall within the range of $10 \div 14 \mu \mathrm{m} / \mathrm{m}$, so they approximate the values of the concrete strains as specified in the tables [3]. The hangar is heated in wintertime, and in summer, the temperature in its inside may reach up to $30^{\circ} \mathrm{C}$, which results in a temperature gradient on the floor slabs. That gradient causes the slabs to dent, especially on the edges, which was demonstrated by measurements [4]. The aging of the material of which the slabs were built, i.e. reinforced concrete, results in its slow contraction. After an almost six year long observation period (cf. Fig. 16), that contraction reached the values within the range of 120 $\mu \mathrm{m} / \mathrm{m}$ (rosette $P$, minimum deformation) $-230 \mu \mathrm{m} / \mathrm{m}$ (rosette $N$, maximum deformation). 


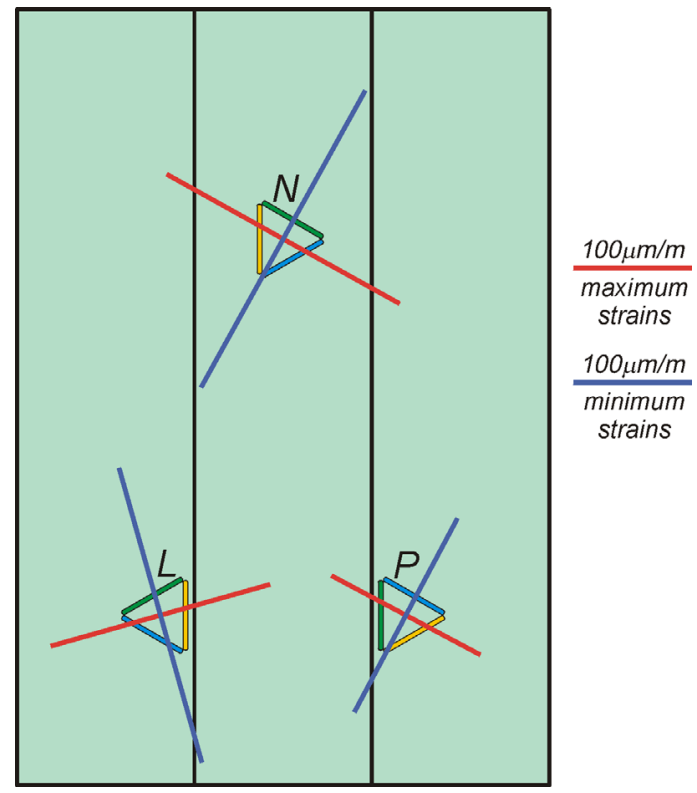

Fig. 16. Contraction of the slab's building material (reinforced concrete) in the installation spot of strain rosettes.

\section{Summary}

The vibrating wire-type measuring equipment used in the measurements demonstrated a high level of reliability and good metrological parameters (including high sensitivity), in spite of its prototypical nature. Thanks to over 50,000 automatically performed strain measurements (for each extensometer), main slab strains were registered for all the instances of parking aircraft inside the hangar that have occurred so far, along with the slab strains caused by changes in the temperature of that slab and the aging of reinforced concrete. Monitoring of the usage strains demonstrated that the strains of the floor slabs in the spots impacted by the load from the wheels of the main undercarriage legs are highly likely to result in discontinuity of concrete (emergence of scratches) in the spots that cannot be accessed for direct observation.

\section{References}

1. http://pl.wikipedia.org/wiki/Airbus_A320 (available Jun.01.2018).

2. Budownictwo ogólne. Tom 1. Materiaty i wyroby budowlane (General construction. Vol. 1. Construction materials and products), Praca zbiorowa pod kierunkiem prof. dr hab. inż. Bogusława Stefańczyka. Arkady Warszawa (2007) (in Polish)

3. Tablice fizyczno-astronomiczne (Physical and astronomical tables), Wydawnictwo Adamantan, Warszawa (1995) (in Polish)

4. A. Kanciruk, Metody tensometryczne w badaniach przemieszczeń, deformacji i zjawisk dynamicznych $w$ gruncie $i$ obiektach budowlanych (Tensometric methods in studies of displacements, deformations and dynamic phenomena in soil and building objects), Archiwum Górnictwa, Wydawnictwo Instytutu Mechaniki Górotworu Polskiej Akademii Nauk, Kraków (2012) (in Polish) 